EPJ Web of Conferences 40, 06005 (2013)

DOI: $10.1051 /$ epjconf/20134006005

(c) Owned by the authors, published by EDP Sciences, 2013

\title{
Improvement of magnetocaloric properties of Gd-Ge-Si alloys by alloying with iron
}

\author{
J. Ferenc ${ }^{1}$, M. Kowalczyk ${ }^{1}$, G. Cieślak ${ }^{1}$, T. Erenc-Sędziak ${ }^{1}$, and T. Kulik ${ }^{1}$ \\ ${ }^{1}$ Faculty of Materials Science and Engineering, Warsaw University of Technology, \\ ul. Wołoska 141, Warsaw, 02-507, Poland
}

\begin{abstract}
The influence of annealing of $\mathrm{Gd}_{5} \mathrm{Ge}_{2} \mathrm{Si}_{2} \mathrm{Fe}_{\mathrm{x}}$ alloys at $1200^{\circ} \mathrm{C}$ and of alloying with various amount of iron on structure as well as thermal and magnetocaloric properties is investigated. It was found that annealing for 1 to 10 hours improves the entropy change, but reduces the temperature of maximum magnetocaloric effect by up to $50 \mathrm{~K}$. Prolonged annealing of the $\mathrm{Gd}_{5} \mathrm{Ge}_{2} \mathrm{Si}_{2}$ alloy results in the decrease of entropy change due to the reduction of $\mathrm{Gd}_{5} \mathrm{Ge}_{2} \mathrm{Si}_{2}$ phase content. Addition of iron to the ternary alloy enhances the magnetocaloric effect, if $\mathrm{x}=0.4-0.6$, especially if alloying is combined with annealing at $1200^{\circ} \mathrm{C}$ : the peak value of the isothermal entropy change from 0 to $2 \mathrm{~T}$ increases from 3.5 to $11 \mathrm{~J} / \mathrm{kgK}$. Simultaneously, the temperature of maximum magnetocaloric effect drops to $250 \mathrm{~K}$. The changes in magnetocaloric properties are related to the change in phase transformation from the second order for arc molten ternary alloy to first order in the case of annealed and/or alloyed with iron. The results of this study indicate that the minor addition of iron and heat treatment to Gd-Ge-Si alloys may be useful in improving the materials' magnetocaloric properties..
\end{abstract}

\section{Introduction}

It is well known that pure gadolinium exhibits interesting magnetocaloric effect (MCE) around room temperature at the second order Curie transition. Also, serious development was achieved by discovering gadoliniumgermanium-silicon alloys $-\mathrm{Gd}_{5} \mathrm{Si}_{\mathrm{x}} \mathrm{Ge}_{4-\mathrm{x}}$, presenting giant magnetocaloric effect (GMCE) at the first-order magneto-structural transition. Comprehensive studies of this group of materials were performed by Pecharsky and Gschneidner [1-4].

There are several groups of alloys possessing good magnetocaloric properties at room temperature. Materials with $\mathrm{Gd}_{5}(\mathrm{Ge}, \mathrm{Si})_{4}$ composition are very promising due to a large entropy change, tunability by Ge:Si ratio, and quite simple manufacturing process. The physical background of good magnetocaloric properties regards the presence of a $1^{\text {st }}$ and a $2^{\text {nd }}$ order phase transitions (crystal structure change and magnetic transition) which are present at around room temperature. Both transitions overlap, what cause significant material's adiabatic temperature change if exposed to magnetic field. It was established that a homogeneous orthorhombic $\mathrm{Gd}_{5} \mathrm{Ge}_{4}$-based solid solution with orthorhombic crystal structure extends from $\mathrm{x}=0$ to 0.8 . In the range $x=0.96-2$ an intermediate phase with monoclinic crystal structure exists in high temperature region. From magnetic and crystallographic studies, it was found that the magnetic transitions in the monoclinic and the $\mathrm{Gd}_{5} \mathrm{Ge}_{4}$-based orthorhombic crystal structures are accompanied by crystalline structure change. Under cooling, the monoclinic structure undergoes first-order magnetic phase transition at the Curie point simultaneously with crystal structure change, from monoclinic to orthorhombic $\mathrm{Gd}_{5} \mathrm{Si}_{4}$-type. The transition causes a very sharp change of magnetization, what corresponds to high magnetocaloric parameters (especially $\Delta S_{\mathrm{M}}$ ). These strong effects are dependent on the actual structure of the alloys, which, in turn, depends on the processing route, including melting and heat treatment. Recent works [5-6] suggested that the small addition of iron to the $\mathrm{Gd}_{5} \mathrm{Si}_{\mathrm{x}} \mathrm{Ge}_{4-\mathrm{x}}$ alloys results in changes in magnetocaloric properties of this type of alloys. This was the starting point to investigate the issue of modification of $\mathrm{Gd}_{5} \mathrm{Si}_{\mathrm{x}} \mathrm{Ge}_{4-\mathrm{x}}$ alloys with $\mathrm{Fe}$. In this work, iron is added to the $\mathrm{Gd}_{5} \mathrm{Ge}_{2} \mathrm{Si}_{2}$ alloy. Additionally, produced materials were subjected to heat treatment at $1200^{\circ} \mathrm{C}$ in order to improve the magnetocaloric properties, as a better homogeneity is expected after annealing.

\section{Experimental}

The $\mathrm{Gd}_{5} \mathrm{Ge}_{2} \mathrm{Si}_{2} \mathrm{Fe}_{\mathrm{x}}$ alloys, where $\mathrm{x}=0,0.2,0.4,0.6,0.8$ and 1 , were arc molten from pure elements $(\mathrm{Gd}: 4 \mathrm{~N}$, Si: $5 \mathrm{~N}, \mathrm{Ge}: 6 \mathrm{~N}, \mathrm{Fe}: 3 \mathrm{~N} 8$ ) in the $5 \mathrm{~N}$ argon atmosphere. The ingots were turned over and remolten 4 times to achieve good homogeneity. Subsequently, the alloys were subjected to isothermal annealing at $1200^{\circ} \mathrm{C}$ in evacuated

This is an Open Access article distributed under the terms of the Creative Commons Attribution License 2.0, which permits unrestricted use, distribution, and reproduction in any medium, provided the original work is properly cited. 
quartz ampoules. The annealing time was from 1 to 100 hours. After annealing, the ampoules were continuously cooled in a stagnant air to room temperature.

The structure of the alloys was investigated with $\mathrm{X}$ ray diffractometry (XRD), using copper tube. The samples were powdered in a mortar. Thermal properties were measured with the DSC calorimeter in zero magnetic field at the temperature range from 213 to $313 \mathrm{~K}$ (from -60 to $+40^{\circ} \mathrm{C}$ ), with the heating and cooling rate of $0.0833 \mathrm{~K} / \mathrm{s}\left(5^{\circ} \mathrm{C} / \mathrm{min}\right)$. For the first-order phase transitions, the transition temperature at $\mathrm{H}=0$ was determined as the temperature of peak on the heat flow curve; for the second-order transitions the inflection point was used instead. The magnetic properties, namely magnetisation vs. temperature at various magnetic field values, were measured with a vibrating sample magnetometer (VSM) being a option to PPMS made by Quantum Design. Temperature was increased from 200 to $400 \mathrm{~K}$ (from -73 to $127^{\circ} \mathrm{C}$ ), the heating rate was the same as in the DSC, and the magnetic field values were: 100 , $200,400,800,1200$ and $1600 \mathrm{kA} / \mathrm{m}$ (equivalents of $0.125,0.25,0.5,1,1.5$ and $2 \mathrm{~T})$. After each $\mathrm{M}=\mathrm{f}(\mathrm{T})_{\mathrm{H}}$ curve recording, the field was removed and the sample was cooled down to the start temperature, then the next field value was applied and the procedure repeated. From the set of thermomagnetic curves recorded with $1 \mathrm{~K}$ step, the set of $(\mathrm{dM} / \mathrm{dT})_{\mathrm{H}}$ was calculated, finally the entropy change $\left(\Delta S_{\mathrm{M}}\right)$ was calculated by integrating $(\mathrm{dM} / \mathrm{dT})_{\mathrm{H}}$ from $\mathrm{H}=0$ to $\mathrm{H}_{\max }$.

\section{Results}

\section{1. $\mathrm{Gd}_{5} \mathrm{Ge}_{2} \mathrm{Si}_{2}$ alloy}

The $\mathrm{Gd}_{5} \mathrm{Ge}_{2} \mathrm{Si}_{2}$ alloy after arc melting consisted mainly of the $\mathrm{Gd}_{5} \mathrm{Ge}_{2} \mathrm{Si}_{2}$ phase, with little amount of $\mathrm{Gd}_{5} \mathrm{Ge}_{3}$ and $\mathrm{Gd}_{5} \mathrm{Ge}_{4}$ phases, as well as traces of unidentified phase(s), as depicted in Fig. 1. However, the value of entropy change was quite low as compared to literature $(\sim-27 \mathrm{~J} / \mathrm{kgK}$ [7]). The reason for this could be the possible inhomogeneities of the chemical composition, suggested by relatively wide diffraction peaks, as well as the presence of impurities and - thus - precipitates. In order to homogenise the alloy, samples were annealed at $1200^{\circ} \mathrm{C}$ for the period from 1 to 100 hours. As the result of annealing for not more than 25 hours, the structure did not change significantly, save for the relative intensities of the peaks of the $\mathrm{Gd}_{5} \mathrm{Ge}_{2} \mathrm{Si}_{2}$ phase. If the samples were annealed for 50 or 100 hours, some peaks from $\mathrm{Gd}_{5} \mathrm{Ge}_{4}$ became more distinct. This could mean that the alloy was overannealed and its desired structure was changed. This assumption was checked with the magnetocaloric properties assessment. Fig. 2, presenting the plots of entropy change of the $\mathrm{Gd}_{5} \mathrm{Ge}_{2} \mathrm{Si}_{2}$ alloy after annealing, proves that the properties of the alloy change upon annealing. The values and temperatures of the maxima of absolute entropy change are repeated in Table 1 for the sake of clarity.

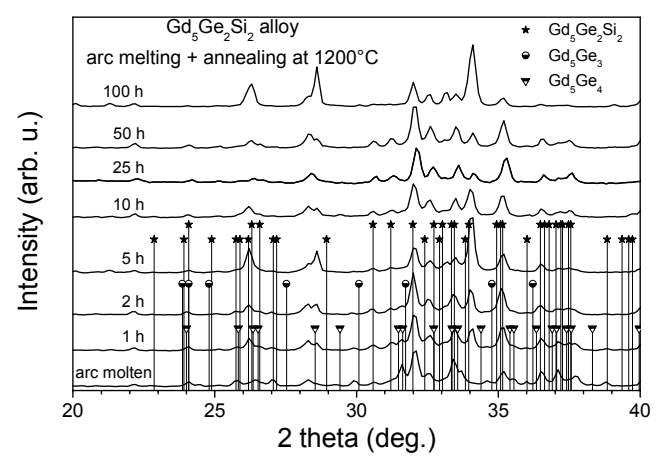

Fig. 1. X-ray diffraction patterns of $\mathrm{Gd}_{5} \mathrm{Ge}_{2} \mathrm{Si}_{2}$ alloy after arc melting and annealing at $1200^{\circ} \mathrm{C}$ for various time.

Annealing at $1200^{\circ} \mathrm{C}$ caused significant changes: the values of entropy and the temperature corresponding to maximum generally increase and shift down, respectively. This suggests that the applied heat treatment may enhance the magnetocaloric effect. It should be noted that for the sample annealed for 100 hours, the properties are similar to these for the arc molten alloy. This difference from the tendency exhibited by the samples annealed for shorter time may be caused by the significant change of structure: there is less $\mathrm{Gd}_{5} \mathrm{Ge}_{2} \mathrm{Si}_{2}$ phase in the overannealed sample, as revealed by structural investigation.

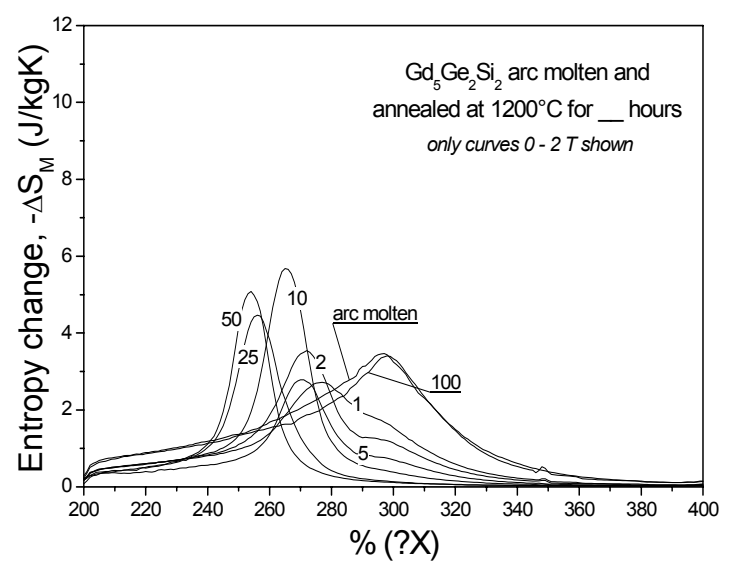

Fig. 2. Entropy change vs. temperature $\mathrm{Gd}_{5} \mathrm{Ge}_{2} \mathrm{Si}_{2}$ alloy after arc melting and annealing at $1200^{\circ} \mathrm{C}$ for various time. Only curves for $\mu_{0} \mathrm{H}$ change from 0 to $2 \mathrm{~T}$ are shown.

In the entropy change vs. temperature curves it may be observed that for the samples annealed for up to 5 hours, there is a tiny "hump" on the right slope of the main peak, which corresponds to the transformation observed for the arc molten alloy. This is not observed for the samples annealed for $10-50$ hours. This could mean that the process of subtle structural changes is finished after 10 hours of heat treatment. However, on the basis of the data gathered in this experiment, it is difficult to determine the character of the structural changes. Nevertheless, the above results suggested that the time of annealing that will be used for further in this study, will be 25 hours. 
Table 1. Maximum entropy change and its temperature for the $\mathrm{Gd}_{5} \mathrm{Ge}_{2} \mathrm{Si}_{2}$ alloy before and after annealing at $1200^{\circ} \mathrm{C}$ for $1-$ 100 hours.

\begin{tabular}{|c|c|c|}
\hline $\begin{array}{c}\text { Annealing } \\
\text { time (hours) }\end{array}$ & $\begin{array}{c}\text { Max. value of }-\boldsymbol{\Delta} \boldsymbol{S}_{\mathbf{M}} \\
(\mathbf{J} / \mathbf{k g K})\end{array}$ & $\begin{array}{c}\text { Temperature of max. } \\
\text { value of }-\boldsymbol{\Delta} \boldsymbol{S}_{\mathbf{M}} \mathbf{( K )}\end{array}$ \\
\hline 0 & 3.5 & 297 \\
\hline 1 & 2.7 & 277 \\
\hline 2 & 3.5 & 272 \\
\hline 5 & 2.8 & 271 \\
\hline 10 & 5.6 & 266 \\
\hline 25 & 4.4 & 257 \\
\hline 50 & 5.1 & 254 \\
\hline 100 & 3.4 & 299 \\
\hline
\end{tabular}

\section{2. $\mathrm{Gd}_{5} \mathrm{Ge}_{2} \mathrm{Si}_{2}$ alloy with $\mathrm{Fe}$ addition}

After arc melting, the alloys with the addition of iron consisted mainly of the $\mathrm{Gd}_{5} \mathrm{Ge}_{2} \mathrm{Si}_{2}$ phase, with a trace amount of $\mathrm{Gd}_{5} \mathrm{Ge}_{4}$ and $\mathrm{Gd}_{5} \mathrm{Ge}_{3}$ phases - see Fig. 3. The lattice parameter gradually increased, reaching, for $\mathrm{x}=1$, only $0.16 \%$. After annealing at $1200^{\circ} \mathrm{C}$ for 25 hours, $\mathrm{Gd}_{5} \mathrm{Ge}_{2} \mathrm{Si}_{2}$ phase is the main part of the structure. Unlike in the arc molten state, diffraction peaks of Fe-containing alloys were shifted to the left, in comparison to the ternary alloy. The lattice expanded progressively, up to $0.45 \%$ for $x=1$. No new phase, induced by introduction of iron, was identified, although for $\mathrm{x}=0.8$ and 1 , new peaks were observed at $2 \Theta=34.33$ and $35.64^{\circ}$ (equivalent to interplanar spacing of 2.6121 and $2.5190 \AA ̊$ ), see Fig. 4.

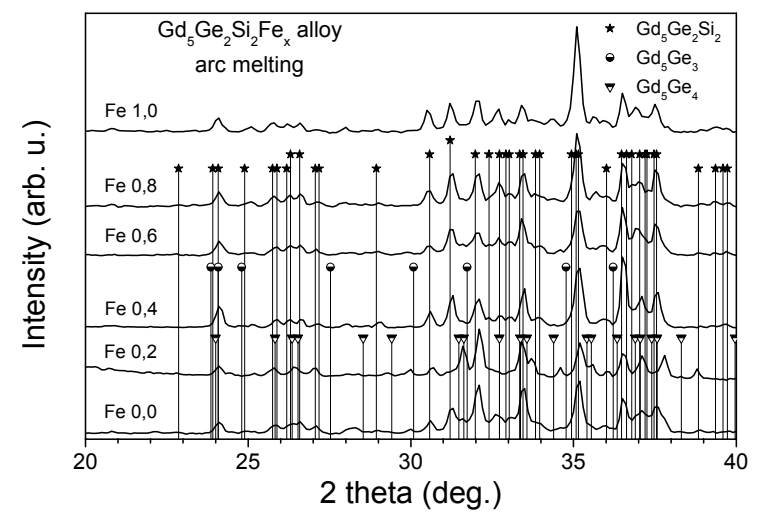

Fig. 3. X-ray diffraction patterns of $\mathrm{Gd}_{5} \mathrm{Ge}_{2} \mathrm{Si}_{2} \mathrm{Fe}_{\mathrm{x}}$ alloys after arc melting.

Subsequently, thermomagnetic curves were recorded, and the entropy change $\left(\Delta S_{\mathrm{M}}\right)$ was calculated for the $\mathrm{Gd}_{5} \mathrm{Ge}_{2} \mathrm{Si}_{2} \mathrm{Fe}_{\mathrm{x}}$ alloys before and after annealing. The plots of entropy change vs. temperature are presented in Figs. 5 and 6. The values of temperature of maximum magnetocaloric effect decrease as the amount of $\mathrm{Fe}$ increases. For the arc molten alloys, the maximum entropy change increases slowly with the Fe addition, but for the alloys after annealing, the peak of $\Delta S_{\mathrm{M}}(\mathrm{T})$ increases two- or threefold for $\mathrm{x}=0.2-0.6$. Further increase of iron content results in the reduction of this increase. This may be due to unfavourable structure of the alloys with a large $\mathrm{Fe}$ addition. The results presented in Fig. 6 indicate that the addition of iron is a very useful way to enhance the $\mathrm{Gd}_{5} \mathrm{Ge}_{2} \mathrm{Si}_{2}$-type alloys' magnetocaloric properties. The magnitude and temperature of the isothermal entropy change may be controlled by the addition of iron to the alloy.

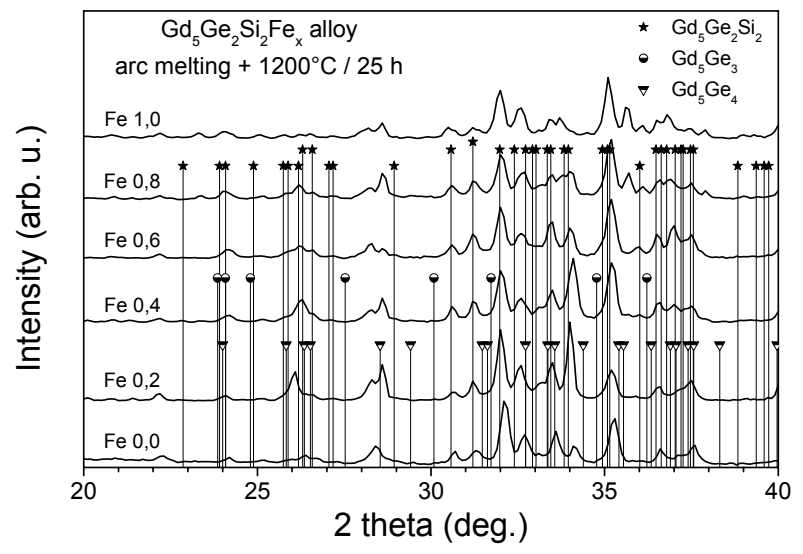

Fig. 4. X-ray diffraction patterns of $\mathrm{Gd}_{5} \mathrm{Ge}_{2} \mathrm{Si}_{2} \mathrm{Fe}_{\mathrm{x}}$ alloys after arc melting and annealing at $1200^{\circ} \mathrm{C}$ for 25 hours.

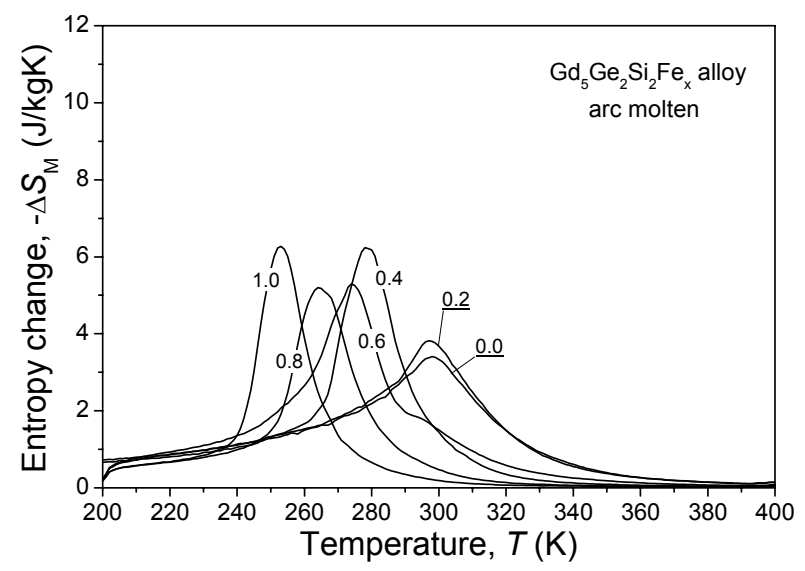

Fig. 5. Entropy change vs. temperature $\mathrm{Gd}_{5} \mathrm{Ge}_{2} \mathrm{Si}_{2} \mathrm{Fe}_{\mathrm{x}}$ alloys after arc melting. Only curves for $\mu_{0} \mathrm{H}$ change from 0 to $2 \mathrm{~T}$ are shown.

The investigated alloys were subjected to heating and cooling in a calorimeter in order to check the phase transitions taking place during the thermal cycles. The calorimetric curves, recorded with the heating/cooling rate of $5^{\circ} \mathrm{C} / \mathrm{min}$, are presented in Figs. 7 and 8 . There is a noticeable difference between the curves for arc molten $\mathrm{x}=0.0$ and 0.2 , and the others: the former ones have inflection points, typical of second-order phase transitions, while the remaining curves have peaks, just like first-order transitions. Furthermore, thermal hysteresis (the difference between the phase transition temperatures calculated for heating and for cooling) was much smaller for $\mathrm{x}=0.0-0.2$ than for $\mathrm{x}=0.4-1.0$, which supports the explanation that the magnetic and structural transitions take place, respectively. The fact that the temperatures of phase transitions from DSC and the temperatures of peak of the entropy change $\left(\Delta S_{\mathrm{M}}\right)$ 
coincide, suggests that the MCE effect in the $\mathrm{x}=0.4-$ 1.0 arises from magnetostructural transition. This conclusion will be verified with the XRD experiment at various temperatures, which is being prepared.

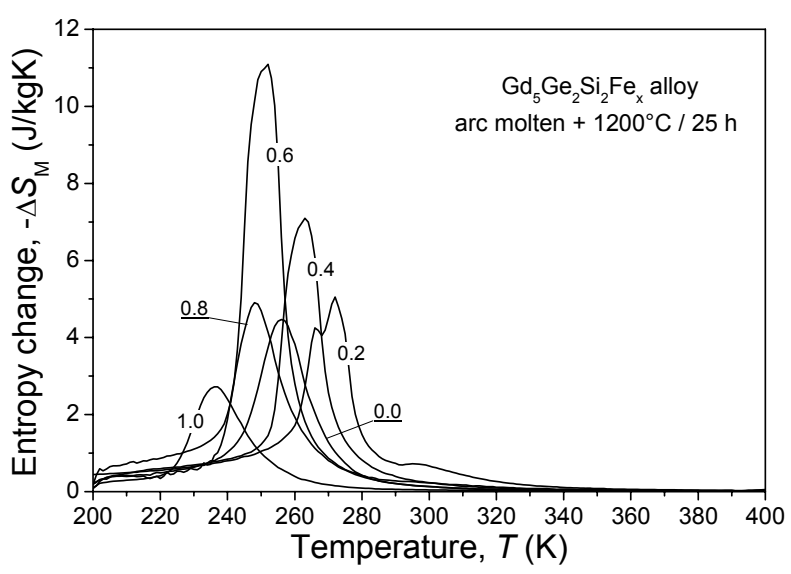

Fig. 6. Entropy change vs. temperature $\mathrm{Gd}_{5} \mathrm{Ge}_{2} \mathrm{Si}_{2} \mathrm{Fe}_{\mathrm{x}}$ alloys after arc melting and annealing at $1200^{\circ} \mathrm{C}$ for various time.

Only curves for $\mu_{0} \mathrm{H}$ change from 0 to $2 \mathrm{~T}$ are shown.

In the case of heat treated alloys, all of them exhibited the peaks, as there was a $1^{\text {st }}$ order transformation, coupled with a magnetic transformation. The thermal hysteresis between heating and cooling was of $9-12 \mathrm{~K}$. The temperature of phase transition was slightly lower than for the arc molten alloys. On the basis of this experiment it is, however, difficult to explain the reason for this apparent change of type of phase transition. In the course of further investigations into this issue, structural investigations at various temperature will be carried out in order to reveal the details of changes in structure that actually take place.

\section{Conclusions}

Annealing of $\mathrm{Gd}_{5} \mathrm{Ge}_{2} \mathrm{Si}_{2}$ alloy slightly enhances the entropy change as compared to arc molten state, but shifts the peak of $\Delta S_{\mathrm{M}}(T)$ to lower temperature by up to $50 \mathrm{~K}$. The addition of little amount of iron also improves the value of entropy change, if iron additive is of $0.4-0.6$ mole per 1 mole of $\mathrm{Gd}_{5} \mathrm{Ge}_{2} \mathrm{Si}_{2}$. Combination of alloying with iron and isothermal annealing at $1200^{\circ} \mathrm{C}$ increases the effect from 3.5 to $11 \mathrm{~J} / \mathrm{kgK}$, although the temperature of maximum magnetocaloric effect is reduced to $250-$ $260 \mathrm{~K}$. The changes in properties may be attributed to an apparent change in the type of phase transition - instead of second order magnetic, first order structural transformation takes place.

\section{Acknowledgements}

This work was supported by the project No. UDAPOIG.01.03.01-00-058/08-00 granted by the Polish Ministry of Science and Higher Education within the Operation Programme Innovative Economy.

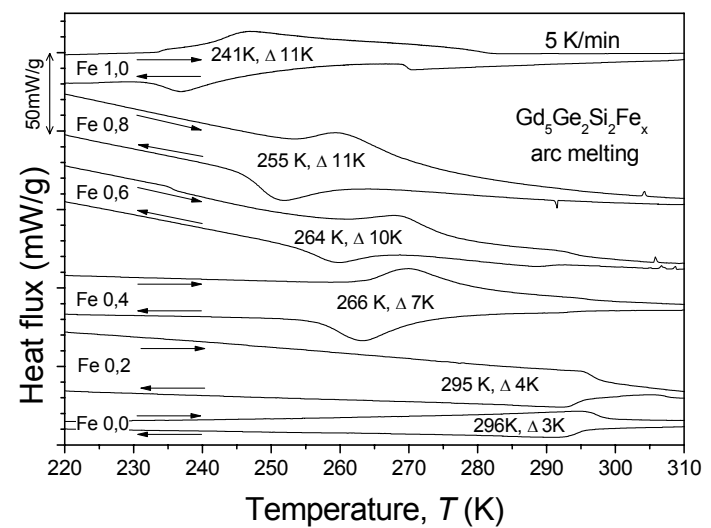

Fig. 7. DSC curves of $\mathrm{Gd}_{5} \mathrm{Ge}_{2} \mathrm{Si}_{2} \mathrm{Fe}_{\mathrm{x}}$ alloys after arc melting.

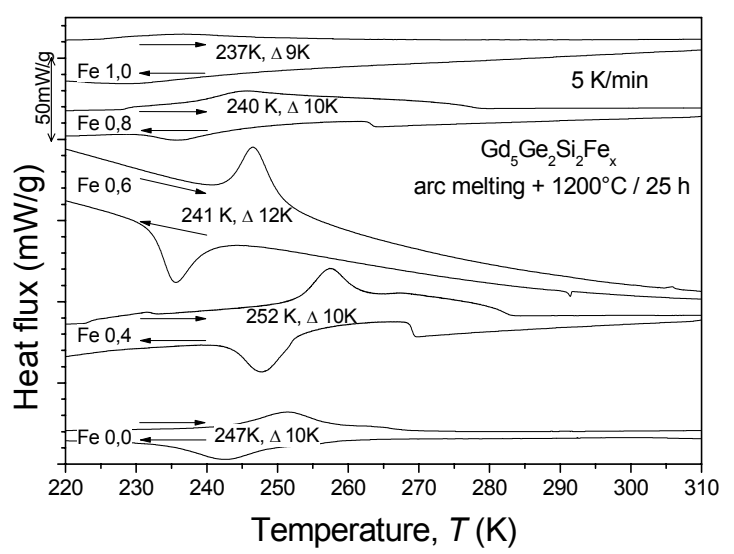

Fig. 8. DSC curves of $\mathrm{Gd}_{5} \mathrm{Ge}_{2} \mathrm{Si}_{2} \mathrm{Fe}_{\mathrm{x}}$ alloy after arc melting and annealing at $1200^{\circ} \mathrm{C}$ for $25 \mathrm{~h}$.

\section{References}

1. V. K. Pecharsky, K. A. Gschneidner Jr., Phys. Rev. Lett., 78(23), pp. 4494-4497 (1997).

2. K. A. Gschneidner Jr., V. K. Pecharsky, A. O. Pecharsky, Zimm, C.B., Mat. Sci. Forum, 315-317, pp. 69-76 (1999).

3. W. Choe, V. K. Pecharsky, A. O. Pecharsky, K. A. Gschneidner Jr., V. G. Young Jr., G. J. Miller, Phys. Rev. Lett., 84(20) pp. 4617-4620 (2000).

4. K. A. Gschneidner Jr., V. K. Pecharsky, Ann. Rev. Mat. Sci., 30, pp. 387-429 (2000)

5. B. Podmiljšak, P.J. McGuiness, N. Mattern, H. Ehrenberg, S. Kobe, IEEE Trans. Magn. 45 (10): 4364-4367 (2009).

6. D. M. Rajkumar, M. Manivel Raja, R. Gopalan, A. K. Singh, V. Chandrasekaran, K. G. Suresh, Intermetallics 18, pp. 518-522 (2010).

7. Pecharsky, A. O., Gschneidner Jr, K. A., Pecharsky, V. K., Jour. App. Phys. 93(8) pp. 4722-4728 (2003) 